\title{
Effect of Foot Reflexology Practice on Acute Pain and Anxiety of Critically ill Patients after
}

\section{Cardiothoracic Surgery}

\author{
Fayza Abdou, Amal Ismael Abd El-Hafez \\ Critical Care and Emergency Nursing Department, Faculty of Nursing, Assuit University, Assuit, Egypt \\ Email id-faiza_critical@yahoo.com,dr_amal_ccn@hotmail.com
}

\section{Abstract}

Background: One of complementary therapy is foot reflexology practice which is effortlessly, un-costly and with little risks or complications and can be considered as part of nursing procedures for acute pain and anxiety after cardiothoracic surgery. Objective: evaluate the effect of foot reflexology practice on acute pain and anxiety of critically ill patients after cardiothoracic surgery. Research hypothesis: The pain and anxiety score among the interventional group who receiving the foot reflexology practice is lower than that of the control group. Research design: a quasi-experimental research design was used. Setting: This study was conducted in Cardiothoracic and Post-Operative Intensive Care Units at Assuit University Hospital. Subjects: sixty patients were enrolled in this study and assigned equally to intervention and control groups during the period of data collection from February 2015 to February 2016. Results: There were significant differences between the mean of pain and anxiety score of both groups at immediately, and 45 minutes indicating lower mean of pain and anxiety level among intervention group who received foot reflexology practice than control group. Conclusion: The intervention group who received foot reflexology practice had lower pain and anxiety level than the control group who didn't received foot reflexology practice after cardiothoracic surgery.

Keywords: foot reflexology, acute pain, anxiety, cardiothoracic surgery.

\section{Introduction}

Cardiac and thoracic surgeries are emerging as an important and common categories of critical care surgeries performed worldwide, ${ }^{[1]}$ Regardless of the procedure performed, successful outcomes depend on optimal postoperative care in the ICU. Most preventable complications following operations have been linked to postoperative problems in the ICU. ${ }^{[2]}$

Pain and anxiety are commonly phenomenon following every category of cardiothoracic surgeries. ${ }^{[3]}$ A negative effect on healing and wound repair has been found on patients with pain and/or anxiety. Many physical and mental energy can be exhausted during pain and anxiety that can lead to increase the patient's tiredness, biochemical activity, stimulation of autonomic nervous system, muscle tension and production of corticosteroids. ${ }^{[4,5]}$

Pain after cardiac surgery is frequently undertreated. In literature the incidence of moderate to severe pain after surgery is $17 \%$ to 40\%. ${ }^{[6,7]}$ A study in 2013 at Aga Khan University Hospital, Nairobi, found that the prevalence of postoperative pain was $58 \%$ within 30minutes, 55.3\%after 24 hours, and $34.7 \%$ after 48 hours after day care surgery. ${ }^{[8]}$ Persistent postoperative pain is an unpleasant sensory and emotional experience and thought to be related nerve injury, and neuroplastic change in CNS. Optimal therapy of physiological and psychological distress during early recovery phase of heart surgery might Optimal pain and anxiety therapy are mandatory to improve pulmonary function, decrease delirium, increase patient satisfaction, drop the surgical complications and shorten the hospital length of stay. ${ }^{[3,6]}$

Nurses should assess and investigate every cardiothoracic patient for presence of pain and anxiety to provide the necessary cares for preventing and dropping complications with proper measures. ${ }^{[4]}$ As mentioned in literatures, the two categories of relieving pain and anxiety are pharmacological and non-pharmacological ways. Now days, an emphasis on non-pharmacological methods to reduce or eliminate anxiety or/and pain on hospital settings. According to the studies, using medications are effective in relieving both pain and anxiety from one side but from the other side the medications had temporary effects. So, there is a need of applying studies regarding the effect of different interventions of non-pharmacological methods on balancing anxiety and pain. ${ }^{[9,10]}$ Most of these interventions are easy, non-invasive and low cost and have little danger and complications that are used alone or along with other methods. ${ }^{[11]}$

One of the branches of non-pharmacological methods is foot reflexology which is done through apply not only massage but also use a firm thumb-walking motion on the reflexes points that reflect all the parts of the body in the form of a small mirror. ${ }^{[12]}$ Factually, foot reflexology is started in Egypt and used as a useful treatment method as pictures show in Egyptian templates from five-hundreds of years. ${ }^{[13]}$ A randomized controlled study evaluating the effects of foot reflexology massage on anxiety in patients following coronary artery bypass graft surgery demonstrated that a significant decrease in anxiety in the experimental group following foot 
International Journal of Innovative Research in Medical Science (IJIRMS)

Volume 03 Issue 08 August 2018, ISSN: 2455-8737, Imp. Factor - 4.102

Available online at - $w w w$.ijirms.in

reflexology. ${ }^{[11]}$ Tsay, Chen (2008) ${ }^{[14]}$ who evaluated the effects of reflexology on postoperative pain and anxiety among patients with digestive cancer found that the patients in the intervention group felt less pain and anxiety. Despite many of researches concluded the effectiveness of foot reflexology it not included in the clinical settings.

The critical care nurse is one of professional health team and has role in control, manage and relieve the post-operative acute pain and/or anxiety after cardiothoracic surgery. Both acute pain and anxiety can be managed by pharmacological and nonpharmacological interventions. Undoubtedly, the medications cost a lot of money nowadays particularly with rising the price of everything in the world. Because of this, there is a need to expand the studies about the use and apply the non-pharmacological interventions in nursing practice. One of complementary therapy is foot reflexology practice which is effortlessly, un-costly and with little risks or complications. Therefore, the study was conducting to evaluate the effect of foot reflexology practice on acute pain and anxiety of critically ill patients after cardiothoracic surgery

\section{Aim of this study to}

1. Compare pain score between the interventional group who received the foot reflexology practice and the control group who did not receive that.

2. Compare level of anxiety between the interventional group who received the foot reflexology practice and the control group who did not receive that.

\section{Research hypothesis}

- The pain score among the interventional group after receiving foot reflexology practice is lower than that of the control group.

- The level of anxiety among the interventional group after receiving foot reflexology practice is lower than that of the control group

- There are differences between the intervention and control groups at the immediate and after 45 minutes of foot reflexology

\section{Subjects and Method}

\section{Study Design}

A quasi-experimental design was used in this study

\section{Setting}

The study was conducted in Cardiothoracic and Post-Operative Intensive Care Units at Assuit University Hospital.

\section{Subjects:}

A convenience sampling of 60 patients was enrolled in this study were assigned to interventional and control groups (30 patients for each) as illustrated in the flow chart (figure 1) during the period of data collection from February 2015 to February 2016.

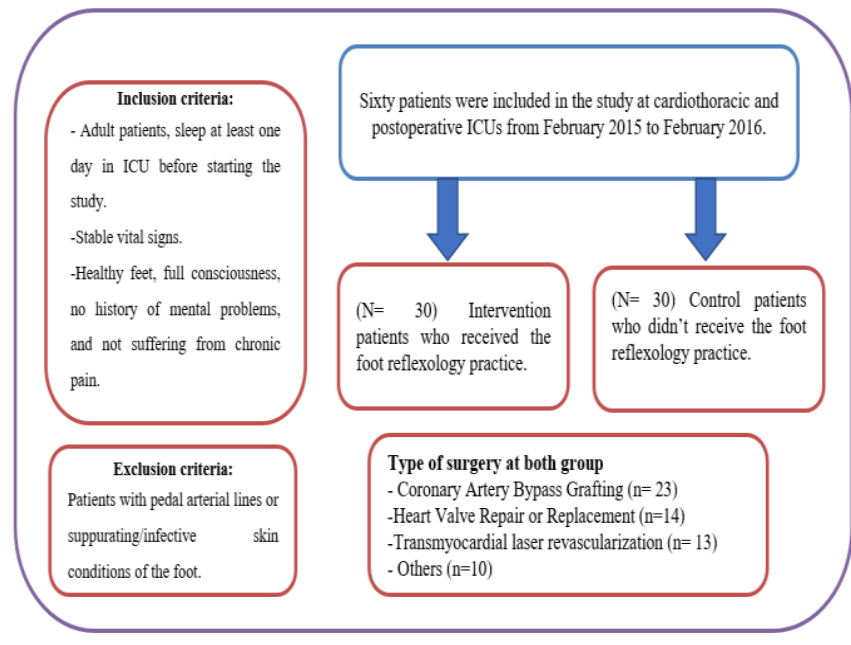

Figure (1): Flow chart of the study subjects.

Tools of the study:

Tool one: Behavioral pain rating scale (BPS)

This tool was adopted from Dehghani $\mathrm{H}$ et al (2014). ${ }^{[15]}$ with internal consistency and reliability Cronbach's alpha was $(r=85)$. It contains three main items for assessment the level of pain if patient intubated or not intubated. The BPS uses a 4 point rating scale, facial expression ranging from relaxed (score 1) and grimacing (score 4), upper arm from no movement (score 1) and permanently retracted (score 4), for the intubated patient assess the Compliance with ventilation ranging from Tolerating movement (score 1) and Unable to control ventilation (score 4), if patient not intubated assess the vocalization ranging from no pain (score 1) and Crying \& sobbing (score 2).

- In addition to patient's data record that includes: age, sex, education level, date of admission to ICU, date of discharge, diagnosis, past history, medications, attached machine and diagnostic lab.

Tool two: Brief psychiatric rating scale (anxiety scale) This tool was adopted from Overall JE et al. $(1992)^{[16]}$ with internal consistency and test-retest reliabilitylity estimates of 0.92 and of 0.75 . The anxiety scale is a 7 -item self-report measure of anxiety severity. The anxiety scale uses a 7-point rating scale, ranging from “(not assessed ), (0), "(not present) (1), ("very mild") (2), "mild", (3), "moderate" (4), "moderately sever" (5), "sever" (6), "extremely severe" (7)

\section{Method}

The study design was accomplished as follow:

- Official approval was taken from the hospital authority to facilitate the research implementation.

- Informed consent of the patients sharing in the study was obtained. The study subjects were assured about the confidentiality. The study subjects were assured about the privacy of their data and the anonymity of the record.

- A pilot study was carried out on 6 patients in the previously mentioned settings to test the feasibility of the tools then necessary modifications were carried out and the results were excluded from the study

- Control group were received the usual care provided to patients after cardiothoracic surgery. 


\section{Actual study:}

- After an initial foot examination, a traditional foot massages using reflexology techniques were carried out in a sequence of massage strokes and gentle pressure to reflexes points on both feet.

- Foot massage was done for three sessions over three days; each session included two sub-sessions; the first one about (5) minutes and the second about (10) minutes for each foot, the actual time the researcher nurse worked on a particular reflex point last from 20 seconds to two minutes or more, the period between the two subsessions is the time needed for obtaining and recording patient pain and anxiety data by behavioral rating scale and brief psychiatric rating scale and minimum time 5 minutes.

* Foot massage protocol was followed in this study to decrease patient pain and anxiety level

\section{Preparation phase:}

$\checkmark \quad$ Being at patients' bedside at afternoon shift because this shift is less noisy in comparison to the morning shift; bedside curtains were drawn.

$\checkmark$ External noise and interruptions were decreased as possible.

$\checkmark$ Comfortable position was assured.

$\checkmark \quad$ Data about patient pain and anxiety were obtained and recorded as base line data before foot massage by using tool one and two

\section{Reflexology phase:}

$\checkmark \quad$ Step 1: Working the underside of the toes.

$\checkmark \quad$ Step 2: Working the ball of the foot.

$\checkmark \quad$ Step 3: Working the upper arch of the foot.

$\checkmark$ Step 3: Working the inside of the foot.

$\checkmark$ Step 4: Working the top of the toes.

$\checkmark$ Step 5: Working the top of the foot

\section{* Massage stroke}

1. Effleurage: The spectrum of this stroke can be determined by pressure, drag, speed, and direction.

- Pressure: light (less than the pressure of the hand) to medium (heavy enough to affect the underlying tissues but not to press through to bone)

- Drag: minimum on dermal layer.

- Speed: Use an effleurage rate of 25.4 to 30.5 $\mathrm{cm} /$ second.

- Direction: always in the direction of venous flow, e.g. rub foot toward the torso.

2. Pétrissage, and friction (strong circular pressure on one point).

\section{* Reflexology pressure point techniques;}

Thumb-walking, Finger-walking, the hook-and-back-up technique, rotating-on a-point

\section{Finishing phase:}

- Twist hands back and forth in a wringing action gently.

- Stretch the hand up toward the toes repeat several times.

- Work over the top and sides of the foot using tiny circular movements.
- Stroke the foot in a gentle upward movement with the fingers of both hands.

- Finish the foot just as you did the hand. Clasp the foot between your hands

$\checkmark \quad$ Data about patient pain and anxiety were obtained and recorded as base line data after foot massage by using tool one and two immediate, after 15 minutes and after 45 minutes

$\checkmark$ Assess the patient attached with mechanical ventilation by anxiety scale through facial expression

\section{Results}

Table 1: Shows the characteristics of the patients assigned to the intervention and control groups. It was found that, $40 \%$ and $53.3 \%$ of intervention group and control group were in age group between 30 and less than 50 years old with no significant differences between both groups. There was a difference in the gender of the participants in each group, with more patients in the intervention group being female $(73.3 \%)$. However, differences in level of education, ICU stay, past medical history between both groups were not statistically significant.

Table 2: Illustrate the comparison between the intervention and control groups regarding facial expression and upper limbs of behavioral pain rating scale at three intervals. It was found that $53.3 \%$ of intervention group had full tightened facial expression compared to $60 \%$ of control group had grimacing expression at immediate time. After 15 minutes, $86.7 \%$ of intervention group had relaxed and $80 \%$ of control group were partially tightened. After 45 minutes, the intervention group still relaxed by $66.6 \%$ and control group had full tightened expression by $60 \%$. There were significant differences between both groups at the three intervals $(\mathrm{p}=<0.001)$ respectively.

Regarding the upper limbs of behavioral pain rating scale, $60 \%$ of intervention group hadn't move their upper limbs and $80 \%$ of control group had fully bent with finger flexion at the immediate time. After 15 minutes, $66.7 \%$ and $86.7 \%$ of intervention and control groups hadn't moved the upper limbs respectively. After $45 \%$ minutes, $86.7 \%$ of intervention group hadn't move their upper limbs compared to $66.7 \%$ of control group had full upper limbs bent with finger flexion. There were significant differences between both groups at the three intervals $(\mathrm{p}=<0.001)$ respectively.

Table 3: Clarifies that the intubated intervention patients distributed in equal percentage between tolerating movement and coughing with movement while $57.14 \%$ of intubated control group were being unable to control ventilation at the intermediate time with significant difference $(\mathrm{p}<0.001)$. After 15 minutes, all of intubated patients among both groups were tolerating movement. After 45 minutes, $83.33 \%$ of intubated intervention patients still tolerate movement while $42.86 \%$ of intubated control patients were fighting ventilator and unable to control ventilation respectively with significant difference $(\mathrm{p}<0.001)$. Regarding the vocalization for non-intubated patients, $66.67 \%$ of intervention patients were not frequently mooning while fifty percent of control patients were frequently mooning at the immediate time with significant difference ( $p<0.001)$. After 15 minutes, $88.9 \%$ and $100 \%$ of nonintubated intervention and control patients were experienced no pain respectively. After 45minutes, all non-intubated intervention 


\section{International Journal of Innovative Research in Medical Science (IJIRMS) \\ Volume 03 Issue 08 August 2018, ISSN: 2455-8737, Imp. Factor - 4.102}

Available online at - $\underline{w w w . i j i r m s . i n}$

patients were reported no pain while half of non-intubated control group were crying and sobbing with significant difference $(\mathrm{p}<0.001)$.

Table 4: Present the comparison between the intervention and control groups regarding total score of behavioral pain rating scale at three intervals. According to the current results, there were significant differences between the mean of pain score in both groups immediately, after 15 minutes and 45 minutes (table 4) indicating lower mean of pain score among intervention patients who received foot reflexology practice.
Table 5: Show the comparison between the intervention and control groups regarding anxiety level scale at three intervals. It was found that the statistical significant differences between the frequencies of anxiety score in both groups at immediate time, after 15 minutes and 45 minutes. This indicating the presence of mild anxiety by $53.3 \%$ of intervention group and moderate anxiety by $60 \%$ of control group (at immediate time), very mild by $60 \%$ and $66.7 \%$ (after 15 minutes), not present by $73.3 \%$ and mild by $66.7 \%$ (after 45 minutes) among intervention group who received foot reflexology practice and control group who didn't received foot reflexology practice, respectively.

Table 1: Distribution of critically ill patients' intervention (who received foot reflexology practice) and control (who not received foot reflexology practice) groups according to their characteristics.

\begin{tabular}{|c|c|c|c|c|c|}
\hline Characteristics & \multicolumn{2}{|c|}{$\mathrm{N}=30$ intervention group } & \multicolumn{2}{|c|}{$\mathrm{N}=\mathbf{3 0}$ control group } & P. value \\
\hline \multicolumn{6}{|l|}{ Age } \\
\hline$<18$ year & 8 & 26.7 & 4 & 13.3 & \multirow{4}{*}{0.439} \\
\hline $18<30$ year & 4 & 13.3 & 6 & 20.0 & \\
\hline $30<50$ year & 12 & 40.0 & 16 & 53.3 & \\
\hline $50 \geq 60$ year & 6 & 20.0 & 4 & 13.3 & \\
\hline \multicolumn{6}{|l|}{ Gender } \\
\hline Male & 8 & 26.7 & 18 & 60.0 & \multirow{2}{*}{$0.009 * *$} \\
\hline Female & 22 & 73.3 & 12 & 40.0 & \\
\hline \multicolumn{6}{|l|}{ level of education } \\
\hline University & 26 & 86.7 & 28 & 93.3 & \multirow{2}{*}{0.389} \\
\hline Secondary school & 4 & 13.3 & 2 & 6.7 & \\
\hline \multicolumn{6}{|l|}{ ICU length of stay } \\
\hline 1-7 days & 18 & 60.0 & 16 & 53.3 & \multirow{3}{*}{0.676} \\
\hline 8-14 days & 10 & 33.3 & 10 & 33.3 & \\
\hline $15-21$ day & 2 & 6.7 & 4 & 13.3 & \\
\hline \multicolumn{6}{|l|}{ Past medical history } \\
\hline \multicolumn{6}{|l|}{ Cardiovascular } \\
\hline Hypertension & 22 & 73.3 & 20 & 66.7 & \multirow{2}{*}{0.573} \\
\hline hypertension \& MI & 8 & 26.7 & 10 & 33.3 & \\
\hline \multicolumn{6}{|l|}{ Respiratory } \\
\hline COPD & 6 & 20.0 & 2 & 6.7 & 0.129 \\
\hline \multicolumn{6}{|l|}{ Metabolic } \\
\hline Hyperglycemia & 8 & 26.7 & 10 & 33.3 & 0.573 \\
\hline
\end{tabular}

Table 2: Comparison between the intervention and control groups regarding facial expression and upper limbs of behavioral pain rating scale at three intervals

\begin{tabular}{|c|c|c|c|c|c|}
\hline Items of behavioral pain rating scale & \multicolumn{2}{|c|}{$\begin{array}{c}\mathrm{N}=30 \\
\text { intervention group }\end{array}$} & \multicolumn{2}{|c|}{$\begin{array}{c}\mathrm{N}=30 \\
\text { control group }\end{array}$} & P. value \\
\hline \multicolumn{6}{|l|}{ I-Facial expression } \\
\hline \multicolumn{6}{|l|}{ Immediate } \\
\hline Patient relaxed & 6 & 20.0 & 0 & 0.0 & \multirow{4}{*}{$<0.001 * *$} \\
\hline Patient partially tightened (e.g. brow lowering) & 8 & 26.7 & 4 & 13.3 & \\
\hline Patient fully tightened (e.g. eyelid closing) & 16 & 53.3 & 8 & 26.7 & \\
\hline Patient grimacing & 0 & 0.0 & 18 & 60.0 & \\
\hline \multicolumn{6}{|l|}{ After 15 minutes } \\
\hline Patient relaxed & 26 & 86.7 & 6 & 20.0 & \multirow{2}{*}{$<0.001 * *$} \\
\hline Patient partially tightened & 4 & 13.3 & 24 & 80.0 & \\
\hline \multicolumn{6}{|l|}{ After 45 minutes } \\
\hline Patient relaxed & 20 & 66.7 & 0 & 0.0 & \multirow{4}{*}{$<0.001 * *$} \\
\hline Patient partially tightened & 10 & 33.3 & 10 & 33.3 & \\
\hline Patient fully tightened & 0 & 0.0 & 18 & 60.0 & \\
\hline Patient grimacing & 0 & 0.0 & 2 & 6.7 & \\
\hline \multicolumn{6}{|l|}{ II-Upper limbs } \\
\hline \multicolumn{6}{|l|}{ Immediate } \\
\hline not moved & 18 & 60.0 & 0 & 0.0 & $<0.001 * *$ \\
\hline
\end{tabular}


International Journal of Innovative Research in Medical Science (IJIRMS)

Volume 03 Issue 08 August 2018, ISSN: 2455-8737, Imp. Factor - 4.102

Available online at - $\underline{w w w . i j i r m s . i n}$

\begin{tabular}{|c|c|c|c|c|c|}
\hline partially bent & 12 & 40.0 & 2 & 6.7 & \\
\hline Fully bent with finger flexion & 0 & 0.0 & 24 & 80.0 & \\
\hline Permanently retracted & 0 & 0.0 & 4 & 13.3 & \\
\hline \multicolumn{6}{|l|}{ after $15 \mathrm{~min}$} \\
\hline not moved & 20 & 66.7 & 26 & 86.7 & \multirow{2}{*}{0.067} \\
\hline partially bent & 10 & 33.3 & 4 & 13.3 & \\
\hline \multicolumn{6}{|l|}{ after $45 \mathrm{~min}$} \\
\hline not moved & 26 & 86.7 & 0 & 0.0 & \multirow{3}{*}{$<0.001 * *$} \\
\hline partially bent & 0 & 0.0 & 10 & 33.3 & \\
\hline Fully bent with finger flexion & 4 & 13.3 & 20 & 66.7 & \\
\hline
\end{tabular}

Table 3: comparison between the intervention and control groups regarding compliance with ventilation and vocalization of behavioral pain rating scale at three intervals

\begin{tabular}{|c|c|c|c|c|c|}
\hline \multirow{2}{*}{$\begin{array}{l}\text { Items of behavioral pain rating scale } \\
\text { III- Compliance with ventilation (for intubated } \\
\text { patients) }\end{array}$} & \multicolumn{2}{|c|}{$\mathbf{N}=\mathbf{3 0}$ intervention group } & \multicolumn{2}{|c|}{$\mathrm{N}=\mathbf{3 0}$ control group } & \multirow[b]{2}{*}{ P. value } \\
\hline & \multicolumn{2}{|c|}{$\mathrm{n}=\mathbf{1 2}$} & \multicolumn{2}{|c|}{$\mathrm{n}=14$} & \\
\hline \multicolumn{6}{|l|}{ Immediate } \\
\hline Tolerating movement & 6 & 50.0 & 0 & 0.0 & \multirow{4}{*}{$<0.001 * *$} \\
\hline Coughing with movement & 6 & 50.0 & 0 & 0.0 & \\
\hline Fighting ventilator & 0 & 0.0 & 6 & 42.86 & \\
\hline Unable to control ventilation & 0 & 0.0 & 8 & 57.14 & \\
\hline \multicolumn{6}{|l|}{ After 15 min } \\
\hline Tolerating movement & 12 & 100.0 & 14 & 100.0 & 0.602 \\
\hline \multicolumn{6}{|l|}{ After $45 \mathrm{~min}$} \\
\hline Tolerating movement & 10 & 83.33 & 0 & 0.0 & \multirow{4}{*}{$<0.001 * *$} \\
\hline Coughing with movement & 2 & 16.66 & 2 & 14.28 & \\
\hline Fighting ventilator & 0 & 0.0 & 6 & 42.86 & \\
\hline Unable to control ventilation & 0 & 0.0 & 6 & 42.86 & \\
\hline III-Vocalization (for non-intubated patients) & \multicolumn{2}{|c|}{$n=18$} & \multicolumn{2}{|c|}{$n=16$} & P. value \\
\hline \multicolumn{6}{|l|}{ Immediate } \\
\hline No pain & 6 & 33.33 & 0 & 0.0 & \multirow{4}{*}{$<0.001 * *$} \\
\hline Mooning not frequent & 12 & 66.67 & 2 & 12.5 & \\
\hline Mooning frequent & 0 & 0.0 & 8 & 50.0 & \\
\hline Crying \& sobbing & 0 & 0.0 & 6 & 37.5 & \\
\hline \multicolumn{6}{|l|}{ After 15 min } \\
\hline No pain & 16 & 88.89 & 16 & 100.0 & \multirow{2}{*}{0.341} \\
\hline Mooning not frequent & 2 & 11.11 & 0 & 0.0 & \\
\hline \multicolumn{6}{|l|}{ After 45 min } \\
\hline No pain & 18 & 100.0 & 0 & 0.0 & \multirow{4}{*}{$<0.001 * *$} \\
\hline Mooning not frequent & 0 & 0.0 & 2 & 12.5 & \\
\hline Mooning frequent & 0 & 0.0 & 6 & 37.5 & \\
\hline Crying \& sobbing & 0 & 0.0 & 8 & 50.0 & \\
\hline
\end{tabular}

Table 4: comparison between the intervention and control groups regarding total score of behavioral pain rating scale at three intervals

\begin{tabular}{|l|c|c|c|}
\hline Total score of behavioral pain rating scale & $\mathbf{N}=30$ intervention group & $\mathbf{N}=30$ control group & P. value \\
\hline Immediate after reflexology phase & $5.3 \pm 1.3$ & $9.7 \pm 1.4$ & $<0.001^{* *}$ \\
\hline 15 min after reflexology phase & $3.5 \pm 0.7$ & $3.9 \pm 0.4$ & $0.013^{*}$ \\
\hline 45 min after reflexology phase & $3.7 \pm 0.9$ & $8.7 \pm 1.3$ & $<0.001^{* *}$ \\
\hline
\end{tabular}

Table 5: comparison between the intervention and control groups regarding anxiety level scale at three intervals

\begin{tabular}{|c|c|c|c|c|c|}
\hline Anxiety scale & \multicolumn{2}{|c|}{$\begin{array}{c}\mathrm{N}=30 \\
\text { intervention group }\end{array}$} & \multicolumn{2}{|c|}{$\begin{array}{c}\mathrm{N}=30 \\
\text { control group }\end{array}$} & P. value \\
\hline \multicolumn{6}{|l|}{ Immediate } \\
\hline Not present & 2 & 6.7 & 0 & 0.0 & \multirow{4}{*}{$0.003 * *$} \\
\hline Mild & 16 & 53.3 & 6 & 20.0 & \\
\hline Moderate & 12 & 40.0 & 18 & 60.0 & \\
\hline Moderately severe & 0 & 0.0 & 6 & 20.0 & \\
\hline \multicolumn{6}{|l|}{ After 15 min } \\
\hline Not present & 0 & 0.0 & 10 & 33.3 & \multirow{2}{*}{$<0.001 * *$} \\
\hline Very mild & 18 & 60.0 & 20 & 66.7 & \\
\hline
\end{tabular}


International Journal of Innovative Research in Medical Science (IJIRMS)

Volume 03 Issue 08 August 2018, ISSN: 2455-8737, Imp. Factor - 4.102

Available online at - $w w w$.ijirms.in

\begin{tabular}{|c|c|c|c|c|c|}
\hline Mild & 12 & 40.0 & 0 & 0.0 & \\
\hline \multicolumn{6}{|l|}{ after $45 \mathrm{~min}$} \\
\hline Not present & 22 & 73.3 & 0 & 0.0 & \multirow{4}{*}{$<0.001 * *$} \\
\hline Very mild & 8 & 26.7 & 6 & 20.0 & \\
\hline Mild & 0 & 0.0 & 20 & 66.7 & \\
\hline Moderate & 0 & 0.0 & 4 & 13.3 & \\
\hline
\end{tabular}

\section{Discussion}

Foot Massage therapy is an ancient therapeutic technique that has been used in most major healing traditions. Recent interest in its role as an adjunct to conventional medical therapy has resulted in an extensive number of clinical trials, with many showing improvement in outcomes such as pain anxiety and muscle tension. Recently, several studies have focused on the role of foot massage therapy in the hospital setting. Of interest is the effect of massage on patients postoperatively, since pain and anxiety may be especially problematic in this group. Therefor the study was conducted to compare the pain score and anxiety level between the interventional group who receive foot reflexology practice and the control group who did not receive that.

Results of the current study revealed that a statistical significant difference between the mean of pain score in interventional group and the control group immediately, after 15 minutes and 45 minutes indicating. The study shows lower mean of pain score among intervention patients who received foot reflexology practice. The same result was found in the study of Cutshall SM. et al $(2010)^{[17]}$ who documented that foot massage therapy improved relaxation in a group of cardiovascular surgery patients who received both foot massage and guided relaxation, and a more recent trial of 104 cardiovascular surgery patients showed reductions in pain and tension for those patients receiving massage therapy. Because of the unique challenges faced by cardiovascular surgery patients (ie, prolonged operative time, considerable musculoskeletal shifting, and positioning requirements), we hypothesized that massage therapy might be particularly beneficial in this patient group.

The result in line with Mohammed HM et al. (2010) ${ }^{[18]}$ who examined the effect of foot and hand massage on anxiety and physiological indicators on 60 patients before the cataract surgery. A reduction of anxiety and an improvement of physiological indices prior the surgeries were reported. Nazari, Ahmadzadeh $(2012)^{[19]}$ examined the effect of foot and hand massage on the reduction of anxiety among patients undergoing the ophthalmology surgery using local anesthesia. Brand, Munroe (2013) ${ }^{[20)]}$ using a quasi-experimental study assessed the effect of foot and hand massage on patients' anxiety among patients undergoing the outpatient surgery. They showed a significant difference in the level of anxiety between hand massage and control groups and believed that hand massage effectively reduced anxiety.

In contrast to the finding of the current study, Gronzales et al $(2010)^{[21]}$ failed to show a reduction in the use of narcotics postoperatively but did show a reduction in the unpleasantness of pain. Taylor et al $(2003)^{[22]}$ evaluated 105 women who underwent abdominal laparotomy and received massage and vibration therapy postoperatively. In this study, mild improvements in pain scores did not reach statistical significance.
Most patients with cardiovascular diseases experience many emotional and psychological problems in the early days of admission to the cardiac care unit (CCU). One of the nursing diagnoses for such patients is anxiety, which is considered a risk factor for coronary artery diseases. The findings of the present study demonstrate that statistical significant differences between the frequencies of anxiety score in both groups and decreased the level of anxiety in intervention group at immediate time, after 15 minutes and 45 minutes from foot reflexology. Most studies showed that reflexology caused deep relaxation, body and mind balance, reduced stress symptoms and created good feelings in patients. The theory of reflexology is based on the principle that energy flows through vertical zones throughout body from organs toward the head. Therefore, massage and stimulation of nerves cause relaxation, reduce tension and as a result returns balance in the body. Kahangi, Moeini(2012 $)^{[23]}$ supported the finding of the current study and confirmed the effect of reflexology on decrease the anxiety level before coronary artery bypass graft surgery.

The same result was found in Hyun et al. (2001) ${ }^{[24]}$ study on patients with ischemic heart diseases and Heidari et al (2015) ${ }^{[25]}$ study on patients with cardiac catheterization showed that hand reflexology reduced anxiety.in contrast to the finding of the current study McVicar et al (2007) ${ }^{[26]}$ found that hand reflexology had no significant effect on patients' anxiety.

Cardiothoracic diseases have been emerging and are becoming a major health problem worldwide. Patients with cardiothoracic disease who do not respond to routine medical treatment will end up with cardiothoracic surgery. Although surgery is beneficial and very essential, it is a highly stressful situation for patient. Foot reflexology is one example of complementary therapies that are cost effective and simple with fewer side effects when compared with drugs. These therapies have been used by nurses to alleviate anxiety, minimize or relieve pain and promote the optimum level of well-being and comfort.

\section{Equations}

The raw data were coded and transformed into coding sheets. The results were checked. Then, the data were entered into SPSS system files (SPSS package version 18) using personal computer. Output drafts were checked against the revised coded data for typing and spelling mistakes. Finally, analysis and interpretation of data were conducted.

The following statistical measures were used:

- Descriptive statistics including frequency, distribution, mean, and standard deviation were used to describe different characteristics.

- Univarate analyses including: T-test, and Z-test were used to test the significance of results of quantitative variables. 
- The significance of the result was at the $5 \%$ level of significance.

\section{Other recommendations}

Based on the findings of the current study, the following recommendations can be suggested:

\subsection{Nursing education}

1. Education and training can be provided to the nurses to perform foot massage for patient to relief pain and anxiety.

2. Appropriate facilities and educational programs of foot reflexology should be provided for the students in faculty of nursing

\section{Booklet can be given regarding foot massage.}

\subsection{Nursing research}

1. The study can be done in large population to generalize the findings.

2. Randomized sampling technique can be done in future study.

3. Additional exploratory studies with a greater precision in sampling and various populations with other type of diseases.

4. Future studies are suggested to use more sessions of the reflexology intervention.

\section{References}

[1] Stephens, R.S. and G.J. Whitman, Postoperative critical care of the adult cardiac surgical patient. Part I: routine postoperative care. Critical care medicine, 2015. 43(7): p. 1477-1497.

[2] Guru, V., et al., Relationship between preventability of death after coronary artery bypass graft surgery and allcause risk-adjusted mortality rates. Circulation, 2008. 117(23): p. 2969-2976.

[3] Albert, N.M., et al., A randomized trial of massage therapy after heart surgery. Heart \& Lung: The Journal of Acute and Critical Care, 2009. 38(6): p. 480-490.

[4] Ahamadi, M., et al., comparing the effect of metatarsus and ankle reflexology massage on patients'state anxiety after coronary artery bypass graft surgery. 2014.

[5] Brunner, L.S., Brunner \& Suddarth's textbook of medical-surgical nursing. Vol. 1. 2010: Lippincott Williams \& Wilkins.

[6] Barr, J., et al., G élinas C, Dasta JF, Davidson JE, Devlin JW, Kress JP, Joffe AM, et al.; American College of Critical Care Medicine. Clinical practice guidelines for the management of pain, agitation, and delirium in adult patients in the intensive care unit. Crit Care Med, 2013. 41: p. 263-306.

[7] Pavlin, D.J., et al., A survey of pain and other symptoms that affect the recovery process after discharge from an ambulatory surgery unit. Journal of Clinical Anesthesia, 2004. 16(3): p. 200-206.

[8] Mwaka, G., S. Thikra, and V. Mung'ayi, The prevalence of postoperative pain in the first 48 hours following day surgery at a tertiary hospital in Nairobi. African health sciences, 2013. 13(3): p. 768-776.
[9] Wang, M.Y., et al., The efficacy of reflexology: systematic review. Journal of advanced nursing, 2008. 62(5): p. 512-520.

[10] Damrongrucktham, C., et al., Effects of hand reflexology on level of pain in abdominal surgery patients. J Nurs Sci Vol, 2009. 27(2): p. S1.

[11] Bagheri-Nesami, M., et al., The effects of foot reflexology massage on anxiety in patients following coronary artery bypass graft surgery: a randomized controlled trial. Complementary therapies in clinical practice, 2014. 20(1): p. 42-47.

[12] Flynn, L., et al., Understanding the role of stimulation in reflexology: development and testing of a robotic device. European journal of cancer care, 2011. 20(5): p. 686-696.

[13] Mackereth, P., S. Dryden, and B. Frankel, Reflexology: recent research approaches. Complementary Therapies in Nursing and Midwifery, 2000. 6(2): p. 66-71.

[14] Tsay, S.-L., et al., Effects of reflexotherapy on acute postoperative pain and anxiety among patients with digestive cancer. Cancer nursing, 2008. 31(2): p. 109115.

[15] Dehghani H, et al . Validity and reliability of behavioral pain scale in patients with low level of consciousness due to head trauma hospitalized in intensive care unit. Arch Trauma Res. 2014

[16] Overall J.E, Gorham D.R \& Shawver J.R.the brief psychiatric rating scale (BPRS) in geropsychatric research:.abnorm.soc.Psychology. 1992, 62:597-602

[17] Cutshall, S.M., et al., Effect of massage therapy on pain, anxiety, and tension in cardiac surgical patients: a pilot study. Complementary therapies in clinical practice, 2010. 16(2): p. 92-95.

[18] MOHAMMAD, H.M., et al., Self-care ability based on Orem's theory in individuals with coronary artery disease. 2010.

[19] Nazari, R., et al., Effects of hand massage on anxiety in patients undergoing ophthalmology surgery using local anesthesia. Journal of caring sciences, 2012. 1(3): p. 129.

[20] Brand, L.R., D.J. Munroe, and J. Gavin, The effect of hand massage on preoperative anxiety in ambulatory surgery patients. AORN journal, 2013. 97(6): p. 708-717.

[21] Gronzales EA, Ledesma RJ, MCAllister Dj, Perry SM, Dyer CA, Maye JP. effect of guided imagery on postoperative outcomes in patients undergoing surgical procedures: arandomized single blind study . J Am AssocNurs Anesth. 2010;78(3):181-8

[22] Taylor, A.G., et al., Effects of adjunctive Swedish massage and vibration therapy on short-term postoperative outcomes: a randomized, controlled trial. The Journal of Alternative \& Complementary Medicine, 2003. 9(1): p. 77-89.

[23] Kahangi, L., M. Moeini, and M. Babashahi, The effects of reflexology on anxiety levels before coronary artery bypass graft surgery. J Research in Behavioural Scienc, 2012. 9(5): p. 163-9.

[24] Hyun KS, Lee HY, Kong SC, et al. The effect of hand massage program on anxiety in patients with ischemic heart diseases. 2001;13(2):340-9

[25] Heidari F,Rejeh N, Heravi-Karimooi M, et al . The effect of stress on foot reflex zone therapy on anxiety, hemodynamic parameters of patients waiting for cardiac 
International Journal of Innovative Research in Medical Science (IJIRMS)

Volume 03 Issue 08 August 2018, ISSN: 2455-8737, Imp. Factor - 4.102

Available online at - $w w w . i j i r m s . i n$

catheterization. Sci JHamadan Nurs Midwifery. (2015;23(2):63-73

[26] Mc Vicar, A., et al., Evaluation of anxiety, salivary cortisol and melatonin secretion following reflexology treatment: a pilot study in healthy individuals. Complementary Therapies in clinical practice, 2007. 13(3): p. 137-145. 